\title{
Pola Komunikasi pada Praktik Meditasi di Sekolah Berbasis Buddhis
}

\author{
Purnomo Ratna Paramita \\ Sekolah Tinggi Agama Buddha Negeri Sriwijaya Tangerang Banten \\ email: purnomo@stabn-sriwijaya.ac.id
}

\begin{abstract}
Abstrak
Penelitian ini bertujuan untuk mendapatkan gambaran tentang pola komunikasi pada penerapan praktik meditasi di sekolah berbasis Buddhis di Banten. Sekolah berbasis Buddhis di Banten terdiri dari: Sekolah Dharma Putra, Sekolah Ariya Metta, Sekolah Atisa Dipamkara, Sekolah Jaya Manggala, Sekolah Bodhisatta, Sekolah Punna Karya, Sekolah Perguruan Buddhi, dan Ehipassiko School. Penelitian ini menggunakan metode kualitatif deskriptif-komparatif dengan teknik pengumpulan data melalui wawancara dan studi dokumen yang kemudian data dianalisis lintas situs menggunakan teknik Miles \& Huberman. Hasil penelitian menunjukkan bahwa praktik meditasi di sekolah berbasis Buddhis di Banten berdasar pada ajaran Buddha dengan tipe pola komunikasi pelengkapan (complementary relationship) dan jenis pola komunikasi interaksional dengan tujuan yang sama yakni membentuk karakter positif siswa sesuai harapan pemerintah, sekolah dan orangtua. Penelitian ini berimplikasi sebagai bukti upaya sekolah Buddhis dalam mensukseskan program penguatan pendidikan karakter yang dicanangkan pemerintah serta dapat menjadi bahan pertimbangan pengambilan kebijakan terkait pola komunikasi pada penerapan meditasi di sekolah-sekolah.
\end{abstract}

Kata kunci: buddha; pendidikan karakter; pola komunikasi; meditasi; sekolah

\section{Communication Patterns on The Meditation Practices in Buddhis-Based Schools}

\author{
Purnomo Ratna Paramita \\ Sekolah Tinggi Agama Buddha Negeri Sriwijaya Tangerang Banten \\ email: purnomo@stabn-sriwijaya.ac.id
}

\begin{abstract}
This study aims to obtain an overview of communication patterns on the application of meditation practice in Buddhist-based schools in Banten. Buddhist-based schools in Banten consist of: Dharma Putra School, Ariya Metta School, Atisa Dipamkara School, Jaya Manggala School, Bodhisatta School, Punna Karya School, Perguruan Buddhi School, and Ehipassiko School. This study used a qualitative descriptivecomparative method with interview and document study techniques which were then analyzed across sites using the Miles \& Huberman technique. The results showed that the practice of meditation in Buddhist-based schools in Banten was based on Buddhist teachings with complementary communication patterns (complementary relationships) and types of interactional communication patterns with the same goal of forming positive character of students according to the expectations of the government, school and parents. Implication of this study are for the proof that Buddhist School succeed government programs (Penguatan Pendidikan Karakter) and for the consideration of policy making related to the communication pattern on the implementation of meditation in schools.
\end{abstract}

Keywords: buddha; character building; communication patterns; meditation; school 


\section{PENDAHULUAN}

Terbitnya Peraturan Presiden nomor 87 tahun 2017 tentang Penguatan Pendidikan Karakter (PPK) menjadi bukti keseriusan pemerintah dalam membangun karakter bangsa. Pada perjalanannya, program PPK tidak selalu berjalan mulus karena tidak sedikit berita-berita tentang kekerasan dan tindak kriminal yang dilakukan oleh sesama siswa atau guru dengan siswa bermunculan di media massa. Sebagaimana dilansir dalam kompas.com tanggal 6 Agustus 2020, 'berdasarkan data Lembaga Perlindungan Saksi dan Korban (LPSK) tahun 2019 lalu, kasus kekerasan seksual yang terjadi di pesantren atau asrama sebanyak 16 kasus, di SD ada 9 kasus, TK dan Universitas masing-masing 3 kasus, SMA dan SLB masing-masing 1 kasus' (Mashabi, 2020). Disamping itu, menurut data Komisi Perlindungan Anak Indonesia (KPAI), lebih dari 100 kasus kekerasan di sekolah, dalam bentuk fisik dan verbal terjadi sejak awal hingga pertengahan Juli 2018. Sekitar 50\% kasus tersebut melibatkan pelajar, baik sebagai korban maupun pelaku, sisanya berkaitan dengan pengajar. Sekolah Dasar tercatat paling sering terjadi kekerasan selama 2018, dengan presentase 50\%, disusul SMA 34,7\% dan SMP 19,3\% (BBC.com, 2018). Data-data tersebut merupakan potret kecil dari tindak kekerasan yang merupakan representasi dari bentuk karakter buruk pelakunya. Karakter tersebut perlu diperbaiki dan ini menjadi tugas bagi setiap elemen masyarakat khususnya satuan pendidikan sebagaimana teramanatkan dalam perpres tersebut.

Sebagai salah satu satuan pendidikan formal yang juga wajib mengimplementasikan PPK, sekolah berbasis Buddhis tampaknya belum banyak terekspose sehingga dalam hal ini dipandang perlu untuk diteliti lebih lanjut kegiatannya dalam mensukseskan program PPK. Sekolah berbasis Buddhis adalah satuan pendidikan formal dasar dan menengah yang tergabung dalam Badan Koordinasi Pendidikan Buddhis Indonesia (BKPBI). Terdapat 9 sekolah di Provinsi Banten yang tergabung dalam $\mathrm{BKPBI}$, antara lain: Sekolah Dharma Putra, Sekolah Dharma Widya, Sekolah Ariya Metta, Sekolah Atisa Dipamkara, Sekolah Jaya Manggala, Sekolah Bodhisatta, Sekolah Punna Karya, Sekolah Perguruan Buddhi, dan Ehipassiko School. Sebagaimana disebutkan dalam pasal 3 perpres tentang PPK tersebut bahwa PPK dilaksanakan dengan menerapkan nilai-nilai Pancasila dalam pendidikan karakter terutama meliputi nilai-nilai religius, jujur, toleran, disiplin, bekerja keras, kreatif, mandiri, demokratis, rasa ingin tahu, semangat kebangsaan, cinta tanah air, menghargai 
prestasi, komunikatif, cinta damai, gemar membaca, peduli lingkungan, peduli sosial dan bertanggungjawab. Berdasarkan penelitian (Sugianto, 2018) ditemukan bahwa sekolah berciri Buddhis di Jakarta dan Tangerang menerapkan pembiasaan meditasi. Nilai-nilai karakter tersebut dapat muncul dan berkembang pada diri siswa melalui pembiasaan praktik meditasi di sekolah. Fakta tersebut didukung oleh hasil penelitian (Nasa and Nuwa, 2019) yang menunjukkan bahwa kegiatan meditasi mampu mengembangkan karakter baik peserta didik.

Saat bermeditasi, siswa dilatih untuk mengamati objek meditasi dalam rentang waktu tertentu. Praktik meditasi tersebut bila dilakukan secara benar dapat efektif dalam mengembangkan kebiasaan sehat dan meningkatkan perilaku interaksi sosial yang adaptif (Pinazo, García-Prieto and García-Castellar, 2020). Selain itu, meditasi anapanasati bila dilakukan setiap hari selama 6 bulan mampu menunjukkan penurunan pada agresi verbal bagi praktisinya (Sivaramappa et al., 2019).

Keberhasilan praktik meditasi tersebut tergantung oleh berbagai faktor yang secara garis besar dibagi menjadi dua, yakni: faktor internal dan faktor eksternal. Faktor eksternal dalam hal ini adalah faktor diluar diri siswa, seperti: guru/siapa yang menyampaikan instruksi meditasi, teknik meditasi/pesan apa yang disampaikan, media apa yang digunakan untuk menyampaikan pesan dan bagaimana cara meminimalisir gangguan yang mungkin dapat muncul saat pesan disampaikan. Serangkaian komponen yang saling terhubung tersebut kemudian disebut sebagai pola komunikasi. Sebagaimana yang tampak pada hasil penelitian (Kurniawan, 2018) menunjukkan bahwa pola komunikasi memiliki pengaruh yang besar bagi anak didik.

Berdasarkan uraian di atas, maka rumusan masalah dalam penelitian ini adalah bagaimana pola komunikasi pada penerapan praktik meditasi di sekolah berbasis Buddhis di Banten. Berdasarkan rumusan masalah tersebut, maka penelitian ini bertujuan untuk mendapatkan gambaran tentang bagaimana sekolah berbasis Buddhis menerapkan pola komunikasi dalam praktik meditasi yang merupakan kegiatan penguatan pendidikan karakter. Melalui hasil penelitian yang didapatkan diharapkan kedepan ada tindak lanjut terkait pola komunikasi pada penerapan praktik meditasi di sekolah baik dari pihak sekolah sendiri, pemerintah maupun dari peneliti yang tertarik terhadap kajian ini.

\section{METODE}

Penelitian ini menggunakan pendekatan kualitatif deskriptif komparatif. Metodologi kualitatif sebagai prosedur 
penelitian yang menghasilkan data deskriptif berupa kata-kata tertulis atau lisan dari orang-orang dan perilaku yang dapat diamati (Bogdan and Taylor, 1975). Penelitian komparatif adalah penelitian yang membandingkan keberadaan satu variabel atau lebih pada dua atau lebih sampel yang berbeda (Sugiyono, 2011). Merujuk pada definisi tersebut maka penelitian ini akan menghasilkan data deskriptif dan perbandingan terkait pola komunikasi pada penerapan praktik meditasi di 8 sekolah berbasis Buddhis di Banten.

Penelitian ini dilakukan di 8 sekolah berbasis Buddhis di provinsi Banten yang tergabung ke dalam Badan Koordinasi Pendidikan Buddhis Indonesia (BKPBI). Sekolah tersebut antara lain: Sekolah Dharma Putra, Sekolah Ariya Metta, Sekolah Atisa Dipamkara, Sekolah Jaya Manggala, Sekolah Bodhisatta, Sekolah Punna Karya, Sekolah Perguruan Buddhi, dan Ehipassiko School. Penelitian ini dilakukan selama bulan Januari 2020 sampai Juni 2020.

Subjek penelitian adalah benda, hal atau orang tempat data untuk variable melekat dan yang dipermasalahkan (Arikunto, 2010) . Subjek penelitian dalam penelitian ini ditentukan menggunakan teknik purposive sampling. Purposive sampling adalah teknik penentuan sampel dengan pertimbangan tertentu (Sugiyono,
2011). Berdasarkan tujuan penelitian, peneliti memutuskan subjek yang tepat untuk penelitian ini antara lain: kepala sekolah, wakil kepala sekolah dan guru mata pelajaran pendidikan agama Buddha di setiap sekolah. Objek penelitian ini adalah pola komunikasi pada penerapan meditasi.

Data penelitian dikumpulkan secara daring melalui wawancara dan studi dokumen dikarenakan kondisi Covid-19 yang masih terjadi sampai saat ini. Data yang terkumpul diuji keabsahannya menggunakan empat kriteria kepercayaan, antara lain: credibility, transferability, dependability dan confirmatory (Moleong, 2011). Keabsahan data diuji melalui proses triangulasi dan member check. Data yang didapatkan kemudian dianalisis menggunakan analisis lintas situs (Miles and A. Michael Huberman, 1992) yang dalam hal ini ada 8 situs/sekolah Buddhis di Banten.

\section{HASIL DAN PEMBAHASAN}

Pola komunikasi pada penerapan meditasi adalah model yang terdiri dari beberapa komponen komunikasi yang saling berhubungan dan berinteraksi dengan tujuan untuk memudahkan penyampaian pesan dan memberikan respon yang sesuai dalam penerapan praktik meditasi. Berdasarkan pengertian tersebut peneliti membuat pedoman wawancara untuk mendapatkan data. Melalui pedoman 
wawancara tersebut kemudian didapatkan data-data. Proses wawancara dilakukan beberapa kali diwaktu yang berbeda-beda untuk memperkuat dan memperdalam data. Data yang terkumpul tersebut kemudian direduksi, disesuaikan dengan data lain seperti dokumentasi kegiatan dan dokumen SOP, jadwal dan lainnya. Selanjutnya ditempatkan sesuai kategorisasi yang telah ditentukan. Data yang telah dikategorisasi diuji keabsahannya dengan proses member check.

Secara keseluruhan, peneliti menemukan pola komunikasi pada penerapan praktik meditasi di sekolah berbasis Buddhis di Banten ini beragam. Setiap sekolah memiliki pola komunikasi yang berbeda-beda walaupun ada juga yang sama. Pola komunikasi merupakan model dari proses komunikasi (West and Lynn $\mathrm{H}$. Turner, 2012). Model komunikasi yang tampak pada hasil penelitian memberikan gambaran data yang telah direduksi dan disajikan guna memudahkan pembaca dalam memahaminya. Dalam model tersebut dapat diidentifikasi setiap komponen yang muncul, seperti: komunikator, media, pesan, gangguan, komunikan, feedback dan evaluasi hasil feedback.

Komponen pertama adalah komunikator yang dalam hal ini berfungsi sebagai penyampai pesan. Komunikator pada pola komunikasi penerapan meditasi di setiap sekolah Buddhis di Banten dapat dilihat pada tabel 1 dibawah ini.

Tabel 1. Komunikator Lintas Situs

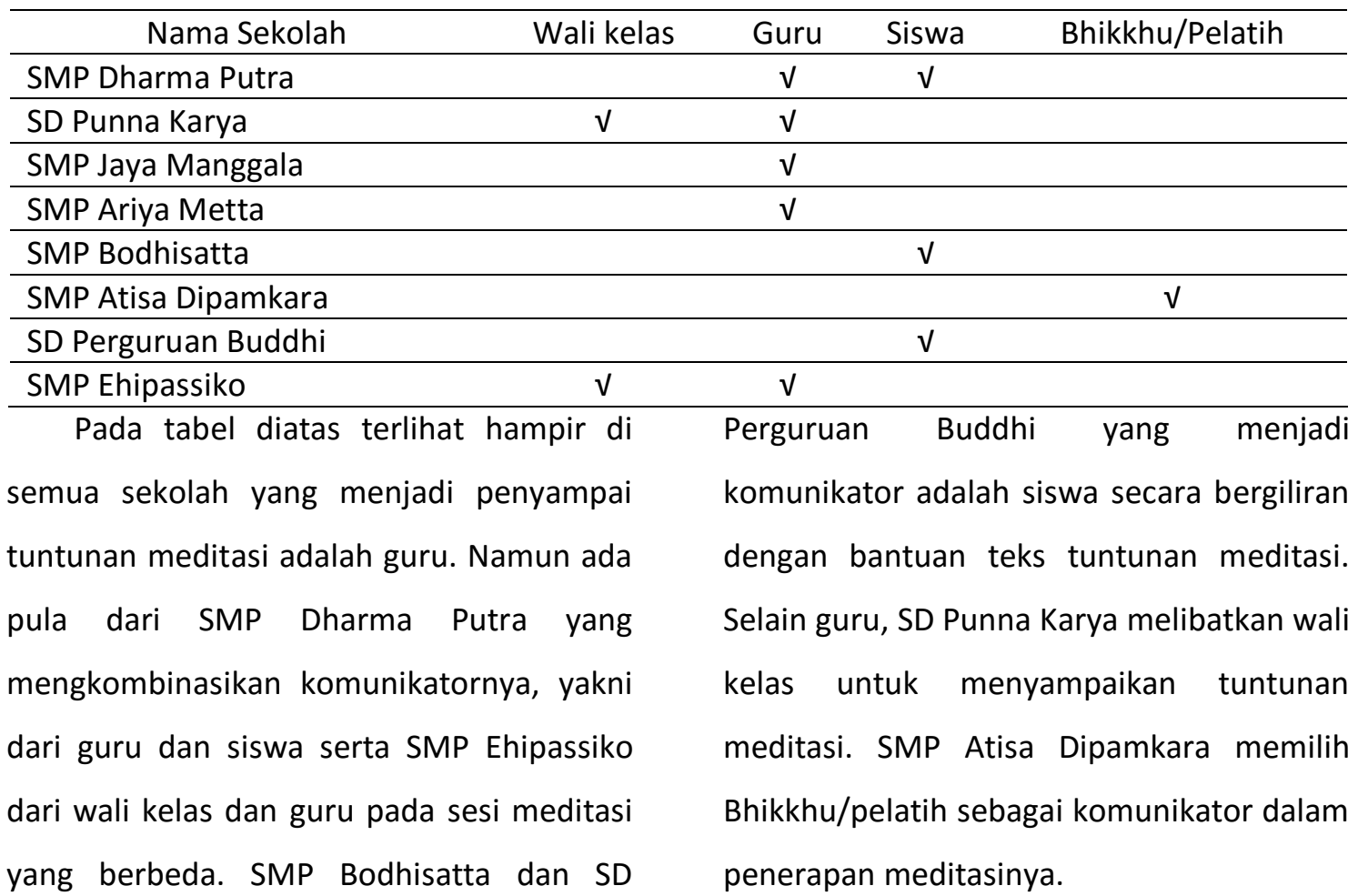


Data tersebut bila ditinjau dari teori obedience (Milgram, 1974), maka figur otoritas seperti Bhikkhu, wali kelas dan guru tepat untuk menjadi komunikator. Teori obedience menyatakan bahwa individu cenderung patuh pada individu lain dalam posisi otoritas. Komunikan (siswa) akan cenderung mengikuti kata-kata yang disampaikan oleh figur otoritas seperti Bhikkhu, wali kelas dan guru. Temuan ini didukung oleh hasil penelitian (Prasetyo and Anwar, 2021) yang menyatakan bahwa komunikasi efektif dapat tercapai bila pesan disampaikan oleh pimpinan yang berkualifikasi sebagai figurehead, leader role dan liaison role. Berbeda bila ditinjau dari teori keseimbangan (Heider, 1958) yang menyatakan bahwa konsep keadaan seimbang menunjukkan sebuah situasi yang di dalamnya unit-unit yang ada dan sentimen-sentimen yang dialami hidup berdampingan tanpa tekanan. Siswa yang menerima bimbingan meditasi dari teman sebayanya akan merasa setara dan tanpa tekanan. Siswa tidak merasa harus patuh pada figur otoritas sehingga menimbulkan unsur tekanan dan keterpaksaan. Siswa akan cenderung mengikuti dan mudah menginternalisasi kata-kata yang disampaikan teman sebayanya seperti siswa sesama sekolahnya. Salah satu syarat terwujudnya komunikasi efektif adalah latar belakang (pendidikan dan budaya), usia, dan etnis. Jika terdapat perbedaan pada tiga hal tersebut, maka proses komunikasi antara komunikator dengan komunikan tidak berjalan lancar (Holton and Dent, 2007).

Berdasarkan hasil penelitian (Muhibah, 2020) salah satu strategi pengembangan pendidikan karakter adalah dengan pendekatan keteladanan. Praktik keteladanan tersebut dilakukan oleh pendidik atau dosen. Hasil penelitian Muhibah mendukung temuan data penelitian ini yang mana sekolah memilih guru sebagai komunikator dalam penyampai pesan meditasi agar siswa dapat meneladani sosok gurunya sebagai upaya pengembangan pendidikan karakter di sekolah Buddhis.

Komponen kedua adalah media yang digunakan komunikator untuk menyampaikan pesannya. Media pada pola komunikasi penerapan meditasi di setiap sekolah Buddhis di Banten dapat dilihat pada tabel 2 dibawah ini.

Tabel 2. Media Lintas Situs

\begin{tabular}{lccccc}
\hline Nama Sekolah & Tanpa speaker & Speaker & $\begin{array}{c}\text { Power } \\
\text { point }\end{array}$ & Proyektor & Genta \\
\hline SMP Dharma Putra & $\mathrm{V}$ & $\mathrm{V}$ & & \\
\hline SD Punna Karya & & $\mathrm{V}$ & & \\
\hline
\end{tabular}




\begin{tabular}{lllll}
\hline SMP Jaya Manggala & $\mathrm{V}$ & $\mathrm{V}$ & \\
\hline SMP Ariya Metta & & & & \\
\hline SMP Bodhisatta & $\mathrm{V}$ & & \\
\hline SMP Atisa Dipamkara & $\mathrm{V}$ & & \\
\hline SD Perguruan Buddhi & $\mathrm{V}$ & & & \\
\hline SMP Ehipassiko & $\mathrm{V}$ & $\mathrm{V}$ & $\mathrm{V}$ & $\mathrm{V}$ \\
\hline
\end{tabular}

Pada tabel diatas terlihat hampir di kelas. Melalui data tersebut tampak bahwa semua sekolah menggunakan bantuan speaker atau pengeras suara untuk membantu penyampaian pesannya. SMP Dharma Putra dan SMP Ariya Metta tidak menggunakan bantuan alat pengeras suara karena tuntunan meditasi disampaikan oleh guru di kelas masing-masing. SMP Ehipassiko selain menggunakan speaker juga memakai alat bantu power point, proyektor dan genta. Berdasarkan wawancara, telaah dokumen jadwal dan SOP mindfulness SMP Ehipassiko, didapatkan gambaran bahwa ada beberapa kegiatan terkait mindfulness, yakni: kegiatan mindful listening setiap hari senin pagi, walking meditation setiap hari rabu pagi, total relaxation setiap hari jumat sore sebelum pulang sekolah dan mindfulness setiap saat selama di sekolah. Beberapa kegiatan tersebut diketahui menggunakan speaker, power point, proyektor dan genta sebagai media komunikasinya. Speaker, power point dan proyektor digunakan saat pengarahan di hari senin pagi, rabu pagi dan jumat sore. Sedangkan genta digunakan untuk pengingat kegiatan mindfulness setiap 30 menit sekali, pada saat awal, istirahat pertama dan akhir pembelajaran di setiap sekolah memiliki kebijakan tersendiri terkait penggunaan media dalam penerapan meditasinya. Penggunaan media tersebut memiliki kelebihan dan kekurangannya masing-masing. Peneliti mengklasifikasikannya menjadi media audio, visual dan audio-visual. Speaker, tanpa speaker (lisan tanpa alat) dan genta masuk kedalam media audio. Sedangkan proyektor dan power point kedalam media visual. Kombinasi keduanya adalah media audio-visual.

Lebih dari 5.000 siswa di Amerika Serikat, Jepang dan Hongkong, pada kelas 5 hingga 12, menunjukkan kecenderungan belajar Visual 29\%, Auditori 34\%, Kinestetik 37\% (Rose and Malcolm J. Nicholl, 2002). Hasil studi tersebut mendukung penggunaan media yang bervariasi mengingat hasil prosentasenya yang seimbang. Dukungan lain ditemukan pada hasil penelitian (Yuli, Subawa and Suparya, 2020) yang menyatakan bahwa penggunaan media audio visual mampu meningkatkan hasil belajar siswa sekolah dasar. Dalam hal ini, bila sekolah mampu menyediakan kombinasi media yang dapat diterima dengan baik oleh siswa visual, auditori dan 
kinestetik, maka pesan dapat mudah untuk diterima.

Komponen ketiga adalah pesan yang disampaikan oleh komunikator kepada komunikan melalui media. Pesan yang disampaikan dalam hal ini adalah tuntunan meditasi untuk siswa maupun guru peserta meditasi. Data tersebut dapat diklasifikasikan seperti yang tampak pada tabel 3 dibawah ini.

Tabel 3. Pesan Lintas Situs

\begin{tabular}{|c|c|c|c|c|}
\hline Nama Sekolah & $\begin{array}{l}\text { Samatha Bhavana } \\
\text { secara umum }\end{array}$ & $\begin{array}{c}\text { Metta } \\
\text { Bhavana }\end{array}$ & Anapanasati & $\begin{array}{l}\text { Vipassana } \\
\text { Bhavana }\end{array}$ \\
\hline SMP Dharma Putra & $\mathrm{V}$ & & & \\
\hline SD Punna Karya & & & $\mathrm{v}$ & \\
\hline SMP Jaya Manggala & & $\sqrt{ }$ & & \\
\hline SMP Ariya Metta & $\mathrm{v}$ & & & \\
\hline SMP Bodhisatta & & $\mathrm{V}$ & & \\
\hline SMP Atisa Dipamkara & $\mathrm{v}$ & & & \\
\hline SD Perguruan Buddhi & $\sqrt{ }$ & & & \\
\hline SMP Ehipassiko & & & & v \\
\hline $\begin{array}{l}\text { Pada SMP Dharma } \\
\text { ditasi diberikan setel }\end{array}$ & $\begin{array}{l}\text { Putra tuntunan } \\
\text { lah pembacaan }\end{array}$ & $\begin{array}{l}\text { Perguruan } \\
\text { Dipamkara. }\end{array}$ & Buddhi dan & SMP \\
\hline
\end{tabular}

namakara patha dan relaksasi. Relaksasi dilakukan dengan duduk tegap, mata dipejamkan dan tangan di atas pangkuan. Relaksasi digunakan agar secara fisik dan batin siswa tidak tegang. Fisik yang tegang akan mempengaruhi batin menjadi tegang sehingga tidak tercapai konsentrasi. Setelah tubuh dan batin rileks selanjutnya disampaikan tuntunan meditasi dan syair Dhammapada. Peneliti melihat tujuan dari meditasinya adalah agar siswa dapat berkonsentrasi dan fokus dalam belajar. Hal ini secara umum merupakan bentuk dari meditasi samatha yakni konsentrasi untuk mendapatkan ketenangan. Selain SMP Dharma Putra, pengguna samatha bhavana secara umum adalah SMP Ariya Metta, SD
SMP Atisa Dipamkara tidak mengatur secara khusus bimbingan meditasinya. Bimbingan meditasi dipercayakan sepenuhnya oleh Bhikkhu Sangha atau pelatih meditasi. Secara umum meditasi dilakukan dengan 3 tahapan, yakni: meditator duduk tenang, memasuki konsentrasi meditasi dengan bimbingan dan terakhir stretching. Metode seperti ini digunakan untuk meminimalisir kesalahan dari pihak sekolah dalam menerapkan meditasi untuk siswa, sehingga sekolah mempercayakan pada Bhikkhu untuk membimbing siswa bermeditasi.

SMP Jaya Manggala dan SMP Bodhisatta menerapkan metta bhavana untuk siswa. Metta bhavana baik digunakan oleh siswa karena cukup mudah untuk 
dilakukan. Siswa diajarkan untuk mendengarkan bimbingan meditasi dari guru dan mempraktikkannya terhadap diri sendiri. Metta bhavana bentuknya lebih konkrit dibandingkan anapanasati. Artinya, siswa lebih mudah memvisualisasikan objek-objek meditasinya dibandingkan anapanasati yang hanya berupa napas. Objek pertama pada meditasi cinta kasih adalah diri sendiri, kemudian objek yang Anda sayangi, objek yang netral dan akhirnya objek/orang yang bermusuhan dengan Anda (Himi, 2010). Hal ini sesuai dengan isi teks renungan pagi SMP Bodhisatta dan SMP Jaya Manggala walaupun tidak ada dalam teks renungan terkait objek yang bermusuhan dengan meditator.

SD Punna Karya menerapkan meditasi anapanasati yang tergambar dari narasi tuntunan meditasinya, yakni: "tarik napas hembuskan pelan-pelan tetap hening". Jean Piaget dalam teorinya tentang tahap perkembangan kognitif membagi 4 tahap perkembangan pada pertumbuhan berpikir logis manusia, antara lain: 1) Tahap sensorimotor: usia $0-1,5$ tahun; 2) Tahap praoperasional: usia $2-7$ tahun; 3) Tahap operasional konkrit: usia 8-14 tahun; dan 4) Tahap operasional formal: usia 14 tahun ke atas (Halford, 2016).

Peneliti menemukan bahwa, bila mengacu pada teori perkembangan kognitif
Piaget, maka objek meditasi yang diterapkan oleh SMP Jaya Manggala dan SMP Bodhisatta (Metta Bhavana) dengan SD Punna Karya (Anapanasati) berbanding terbalik. Metta bhavana memiliki objek yang lebih konkrit/nyata dibandingkan anapanasati yang abstrak. Siswa SD yang berusia sekitar 6-12 tahun cenderung berpikir konkrit yang mana hal ini sesuai dengan objek meditasi yang nyata pula seperti dalam metta bhavana dan siswa SMP yang berusia sekitar 12 tahun keatas memiliki kemampuan berpikir abstrak yang lebih baik sehingga objek napas dalam anapanasati akan mudah untuk dilakukan. Temuan tersebut didukung oleh hasil penelitian (Mauliya, 2019) bahwa siswa SMP memasuki tahap operasi formal yang mana salah satu karakteristiknya adalah mampu menerima materi yang bersifat abstrak.

SMP Ehipassiko menerapkan meditasi vipassana untuk siswa dan guru di lingkungan sekolah. Peneliti melihat meditasi yang diterapkan di sekolah ini tidak terbatas pada satu posisi meditasi. Siswa dan semua warga sekolah dibimbing untuk tetap memunculkan kesadaran dalam posisi apapun, baik itu duduk, berbaring, berjalan dan berdiri. Sekolah setiap hari melakukan sosialisasi dan penguatan terhadap siswa dan guru terkait 
pelaksanaan meditasi vipassana atau mindfulness setiap saat di sekolah.

Praktik mindfulness diterapkan secara menyeluruh mulai dari awal pembelajaran di jam pertama pukul 07.15, pembacaan doa pembuka, mindfulness setiap 30 menit sekali, sesi istirahat, sampai doa penutup pembelajaran pukul 14.30 yang mana setiap mulai dan akhir kegiatan tersebut ditandai oleh bunyi genta baik secara manual yang dibunyikan oleh guru maupun otomatis oleh sistem dengan bantuan speaker. Kegiatan mindfulness berupa praktik sadar penuh pada napas masuk dan napas keluar. Teknik ini sesuai dengan ajaran Buddha dalam Satipatthana Sutta tentang 4 landasan perhatian. Sadar penuh pada napas masuk yang dipraktikan di SMP Ehipassiko merupakan bagian dari praktik kayanupassana satipatthana.

Dalam proses mindfulness tersebut pesan disampaikan secara bervariasi dan simultan, baik dari sesi khusus sehari sekali berupa kata-kata renungan dalam mindful

Tabel 4. Gangguan Lintas Situs listening, walking meditation dan total relaxation maupun sesi rutin setiap 30 menit sekali melalui suara genta. Proses ini tidak lain bertujuan untuk mewujudkan pembiasaan berupa hidup berkesadaran sehingga terjadi internalisasi dan otomatisasi praktik berkesadaran sekalipun siswa telah berada diluar area sekolah. Tujuan tersebut sejalan dengan makna meditasi vipassana bagi mahasiswa STAB Syailendra yang mana merupakan bentuk pengendalian diri agar tidak hanyut dalam perasaan senang, marah, benci, kebodohan, serakah, serta tidak melekat dengan masalah yang ada dan selalu sadar setiap saat dalam melakukan segala sesuatu (Setyadi, Kustiani and Sukodoyo, 2020).

Komponen selanjutnya adalah gangguan dan kendala yang kerap muncul pada proses komunikasi. Gangguan meditasi yang kerap muncul di setiap sekolah dapat dilihat pada tabel 4 dibawah ini:

\begin{tabular}{|c|c|c|c|c|c|}
\hline Nama Sekolah & Komunikator & Komunikan & Lokasi & $\begin{array}{l}\text { Suara } \\
\text { bising }\end{array}$ & $\begin{array}{c}\text { Waktu/ } \\
\text { Durasi }\end{array}$ \\
\hline SMP Dharma Putra & & $\mathrm{v}$ & $\mathrm{v}$ & & \\
\hline SD Punna Karya & & $\sqrt{ }$ & & & \\
\hline SMP Jaya Manggala & & $\mathrm{v}$ & & & \\
\hline SMP Ariya Metta & & & & $\mathrm{v}$ & \\
\hline SMP Bodhisatta & $\mathrm{v}$ & $\mathrm{v}$ & & & \\
\hline SMP Atisa Dipamkara & & $\sqrt{ }$ & & & \\
\hline SD Perguruan Buddhi & & & & & $\mathrm{v}$ \\
\hline SMP Ehipassiko & & & & & $\mathrm{v}$ \\
\hline
\end{tabular}


SD Punna Karya, SMP Jaya Manggala dan SMP Atisa Dipamkara memiliki gangguan yang sama yakni dari komunikan. Komunikan dalam hal ini adalah siswa. Siswa yang merasa mengantuk, mengobrol, ketidakmampuan untuk rileks, berkonsentrasi dan tidak bisa mengikuti aturan meditasi merupakan beberapa gangguan yang disebabkan oleh siswa sebagai komunikan. Gangguan yang berasal dari kondisi jiwa siswa merupakan gangguan psikologis dalam proses komunikasi (Matuzzahara, P., Sardi, I., \& Nurfathiya, 2020).

SMP Dharma Putra memiliki gangguan selain dari komunikan adalah lokasi. Lokasi yang digunakan untuk meditasi salah satunya adalah cetiya. Dalam hal ini cetiya memiliki ukuran yang tidak luas sehingga menjadi kendala dalam bermeditasi berjalan.

SMP Bodhisatta memiliki gangguan selain dari komunikan adalah komunikator. Komunikator dalam hal ini adalah pemimpin meditasi. Pemimpin meditasi dianggap memiliki suara yang kurang jelas dan terkadang salah dalam membaca teks renungan meditasi sehingga pesan yang disampaikan tidak mampu diterima dengan sempurna oleh siswa sebagai komunikan.

SMP Ariya Metta memiliki gangguan dalam praktik meditasinya berupa suara bising pesawat terbang. Suara bising pesawat terbang timbul karena lokasi sekolah yang berdekatan dengan bandar udara Soekarno Hatta. Suara bising termasuk kedalam gangguan fisik yang menghambat tersampaikannya pesan dari komunikator ke komunikan (Anggraini, 2018).

SD Perguruan Buddhi dan SMP Ehipassiko memiliki gangguan yang sama yakni durasi waktu meditasi. Durasi waktu meditasi dianggap terlalu sedikit karena dikawatirkan akan memotong jam belajar efektif maupun kegiatan lain. Waktu meditasi yang sedikit tersebut sulit dimanfaatkan secara maksimal untuk mencapai keberhasilan meditasi.

Komponen selanjutnya adalah komunikan. Komunikan adalah seseorang yang menerima pesan dari komunikator. Komunikan pada setiap sekolah dapat dilihat pada tabel 5 berikut ini.

Tabel 5. Komunikan Lintas Situs

\begin{tabular}{lccc}
\hline \multicolumn{1}{c}{ Nama Sekolah } & Siswa & Guru & Semua Warga Sekolah \\
\hline SMP Dharma Putra & $\mathrm{V}$ & & \\
\hline SD Punna Karya & $\mathrm{V}$ & $\mathrm{V}$ & \\
\hline SMP Jaya Manggala & $\mathrm{V}$ & & \\
\hline SMP Ariya Metta & $\mathrm{V}$ & $\mathrm{V}$ \\
\hline SMP Bodhisatta & $\mathrm{V}$ & \\
\hline SMP Atisa Dipamkara & $\mathrm{V}$ & $\mathrm{V}$ \\
\hline
\end{tabular}




\begin{tabular}{|c|c|c|c|}
\hline SD Perguruan Buddhi & $\mathrm{v}$ & $\mathrm{v}$ & \\
\hline SMP Ehipassiko & $\mathrm{v}$ & $\mathrm{v}$ & $\mathrm{V}$ \\
\hline
\end{tabular}

Banten memberikan tuntunan meditasi untuk para siswa. Dari 8 sekolah tersebut, ada 5 sekolah yang juga menerapkan meditasinya untuk para guru disamping siswa. 5 sekolah tersebut, antara lain: SD Punna Karya, SMP Ariya Metta, SMP Atisa Dipamkara, SD Perguruan Buddhi dan SMP Ehipassiko. Terdapat 1 sekolah yang menerapkan meditasinya untuk seluruh warga sekolah, yakni: SMP Ehipassiko.

Siswa yang berperan sebagai komunikan di sekolah cenderung menjadi bagian yang perlu mengikuti apa yang diarahkan oleh guru sebagai komunikator. Guru dan pengambil kebijakan sekolah yang bertujuan untuk kemajuan siswa sehingga dalam posisi ini siswa perlu menerima apa yang sudah dibuat untuknya. Pola seperti ini mendukung tipe pola komunikasi pelengkap (complementary) yang mana antara komunikator dengan komunikan berjalan saling mendukung sebagaimana disampaikan oleh Palo Alto Grup (Littlejohn and Karen A Foss, 2009).

Komponen terakhir adalah feedback atau umpan balik. Umpan balik dapat berupa verbal, nonverbal, sengaja maupun tidak disengaja (West and Lynn H. Turner, 2012). Hasilnya dapat dilihat pada tabel 6 dibawah ini.

Tabel 6. Umpan Balik Lintas Situs

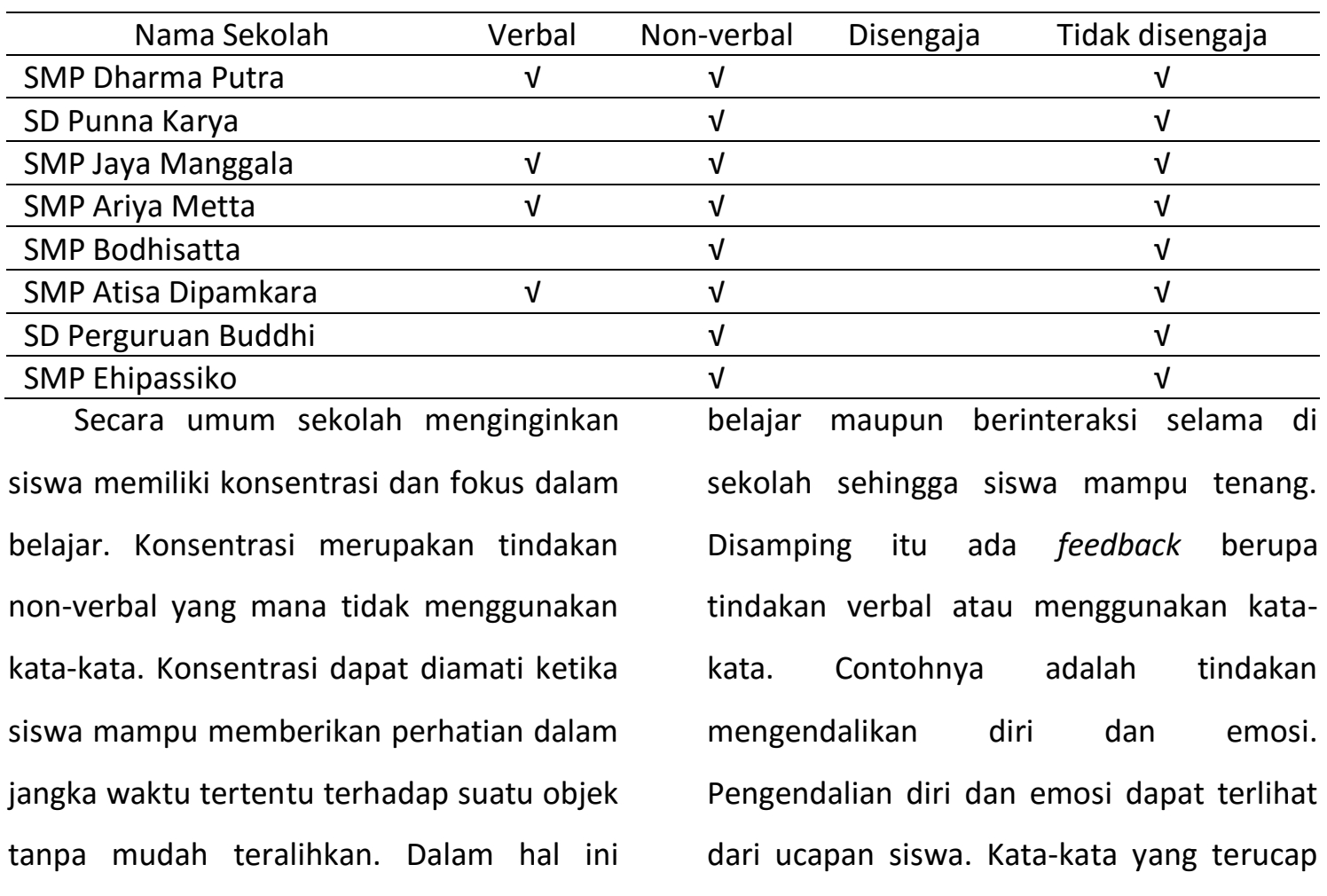

konsentrasi digunakan siswa dalam proses 
dapat diidentifikasi unsur emosi dan pengendalian dirinya.

Hasil menunjukkan bahwa ada perbedaan dari data yang didapatkan dari informan dengan pernyataan West dan Turner tentang umpan balik. Umpan balik dapat berupa verbal, nonverbal, sengaja maupun tidak disengaja (West and Lynn $\mathrm{H}$. Turner, 2012). Sedangkan data dari informan menunjukkan tidak ada feedback berupa tindakan yang disengaja.

Sekolah dalam hal ini mengukur keberhasilan perubahan sikap siswa dilihat dari kealamiahan tindakannya. Guru dapat Tabel 7. Tipe Pola Komunikasi Lintas Situs melihat mana tindakan siswa yang alami dilakukan dengan yang berpura-pura. Hal ini dapat terlihat dari perilaku siswa seharihari, apakah suatu tindakan tersebut dilakukan secara kontinyu tanpa perintah atau hanya saat-saat tertentu khususnya saat ada guru yang memperhatikan. Semua feedback ini bermuara pada satu tujuan yakni pembentukan karakter yang baik sesuai dengan yang diharapkan pemerintah, sekolah dan orangtua.

Hasil penelitian ini jika ditelaah dari segi tipe pola komunikasi, maka dapat terlihat pada tabel 7 berikut.

\begin{tabular}{|c|c|c|}
\hline Nama Sekolah & Hubungan Simetris & Hubungan Pelengkapan \\
\hline SMP Dharma Putra & & $\mathrm{V}$ \\
\hline SD Punna Karya & & $\sqrt{ }$ \\
\hline SMP Jaya Manggala & & $\mathrm{V}$ \\
\hline SMP Ariya Metta & & $\mathrm{V}$ \\
\hline SMP Bodhisatta & & $\sqrt{ }$ \\
\hline SMP Atisa Dipamkara & & $\sqrt{ }$ \\
\hline SD Perguruan Buddhi & & $\mathrm{v}$ \\
\hline SMP Ehipassiko & & $\mathrm{V}$ \\
\hline
\end{tabular}

Palo Alto Group dalam (Littlejohn and Karen A Foss, 2009) menjelaskan dua tipe pola komunikasi, antara lain: hubungan simetris (symmetrical relationship) dan pelengkapan (complementary). Hubungan simetris (symmetrical relationship) merupakan hubungan dengan pertentangan kekuasaan yaitu salah satu lawan bicara menonjolkan kendali dan yang lainnya juga memaksakan kendali. Sedangkan hubungan pelengkap (complementary relationship) merupakan hubungan dengan cara berlawanan. Maksudnya, ketika ada yang mendominasi, maka yang lainnya akan patuh.

Pada konteks komunikasi pada penerapan meditasi khususnya di sekolah tampak bahwa kecenderungan yang terjadi adalah hubungan pelengkapan (complementary). Kebijakan awal sekolah telah menginginkan adanya perubahan sikap dan karakter siswa melalui praktik meditasi. Oleh sebab itu, kegiatan meditasi dikondisikan untuk siswa dapat mematuhi 
tuntunan meditasi yang diberikan oleh guru agar tujuan dapat tercapai. Siswa sebagai komunikan tidak dikondisikan untuk dapat memaksakan kehendak terhadap guru sebagai komunikator. Dalam hal guru yang menjadi komunikan, tentu guru sudah memahami maksud dari meditasi dan kecil kemungkinan untuk muncul usaha memaksakan kehendak terhadap komunikator seperti pada hubungan simetris.

Fakta ini sejalan dengan hasil penelitian (Muin, 2013) yang mana praktik pembiasaan dan keteladanan menjadi salah

Tabel 8. Jenis Pola Komunikasi Lintas Situs satu strategi penguatan karakter. Hubungan pelengkapan memudahkan siswa untuk meneladani sikap dan kata-kata guru. Hal ini mendukung dalam pembentukan karakter melalui meditasi yang mana pesannya disampaikan dengan tipe pola komunikasi pelengkapan.

Terdapat tiga jenis pola atau model komunikasi yang utama, yaitu: pola komunikasi linier, interaksional dan transaksional (Kristofer and Susanto, 2019). Pada tabel 8 dibawah ini dapat terlihat jenis pola komunikasi lintas situs.

\begin{tabular}{|c|c|c|c|}
\hline Nama Sekolah & Linier & Interaksional & Transaksional \\
\hline SMP Dharma Putra & & $\mathrm{V}$ & \\
\hline SD Punna Karya & & $\mathrm{v}$ & \\
\hline SMP Jaya Manggala & & V & \\
\hline SMP Ariya Metta & & $\sqrt{ }$ & \\
\hline SMP Bodhisatta & & $\sqrt{ }$ & \\
\hline SMP Atisa Dipamkara & & $\mathrm{V}$ & \\
\hline SD Perguruan Buddhi & & $\sqrt{ }$ & \\
\hline SMP Ehipassiko & & $\mathrm{V}$ & \\
\hline
\end{tabular}

Pola komunikasi pada penerapan komunikan dapat menjadi komunikator saat

praktik meditasi di sekolah berbasis Buddhis menyampaikan pesan berupa feedback hasil di Banten cenderung memiliki jenis pola meditasi. Feedback tersebut dapat berupa komunikasi interaksional. Pola komunikasi tindakan verbal dan non verbal baik saat interaksional lebih ditekankan proses praktik meditasi maupun dalam keseharian komunikasi dua arah di antara komunikator. di sekolah. Dalam konteks meditasi tentu Komunikasi berlangsung dari pengirim kepada penerima dan dari penerima kepada pengirim.

Proses interaksional ini tergambar pada setiap model yang disajikan pada hasil penelitian. Pada model tersebut terlihat feedback yang muncul cenderung lebih dalam bentuk non-verbal mengingat dalam meditasi tidak dianjurkan untuk berbicara. Bentuk feedback verbal dapat terlihat saat komunikan selesai bermeditasi dan beraktivitas sehari-hari di sekolah. Dari hasil 
meditasi tersebut, kemudian yang diawal menjadi komunikator berubah menjadi komunikan dan menerima feedback tersebut. Sampai disini komunikator yang mampu menjadi komunikan adalah komunikator seorang guru, karena komunikator seorang siswa tidak berkepentingan untuk menerima pesan dari feedback yang dihasilkan. Siswa hanya menyampaikan tuntunan meditasi berdasarkan teks meditasi yang telah disiapkan oleh guru atau sesuai arahan guru.

Ditemukan sebuah pola komunikasi
yang mana seorang komunikator
menyampaikan pesan berupa instruksi
meditasi kepada para komunikan yang
dikenal sebagai bentuk pola komunikasi
kelompok/massa, kemudian komunikan
memproses informasi tersebut secara
internal dalam diri sendiri dan membentuk
pola komunikasi intrapersonal. Setelah
komunikan memproses informasi tersebut
kemudian dapat dimungkinkan berbagai
reaksi muncul atas proses informasi
tersebut. Guru dan pihak sekolah mengukur
melalui pengamatan terhadap siswa. Siswa
yang memiliki sikap tenang dan dapat fokus
dalam sesi meditasi dan pembelajaran
dapat dianggap berhasil dalam upaya
menerima dan memproses pesan meditasi
tersebut.

\section{SIMPULAN DAN SARAN}

Berdasarkan uraian di atas maka dapat disimpulkan bahwa pola komunikasi pada penerapan praktik meditasi di sekolah berbasis Buddhis di Banten didapatkan dari setiap komponen komunikasi yang saling berinteraksi dengan tujuan untuk memudahkan penyampaian pesan dan memberikan respon yang sesuai. Komponen komunikasi tersebut antara lain: komunikator, media, pesan, gangguan, komunikan dan feedback.

Komunikator dalam praktik meditasi di sekolah berbasis Buddhis di Banten sebagian besar dilakukan oleh guru termasuk Bhikkhu. Media yang digunakan untuk menyampaikan tuntunan meditasi adalah pengeras suara/speaker. Pesan yang disampaikan komunikator secara umum berisi tuntunan meditasi samatha bhavana atau meditasi untuk ketenangan batin. Gangguan yang muncul saat meditasi secara umum berasal dari komunikan yang dalam hal ini adalah siswa penerima tuntunan meditasi (meditator). Hal ini disebabkan oleh siswa yang terkadang mengantuk dan kurang disiplin mengikuti peraturan meditasi seperti datang terlambat, berbicara dan bercanda, disamping itu kemampuan konsentrasi siswa yang berbeda-beda sehingga berpengaruh pada keberhasilan penerimaan pesan meditasi. Komunikan dalam praktik meditasi ini 
seluruhnya adalah siswa disamping beberapa guru di beberapa sekolah. Feedback pada praktik meditasi yang ditimbulkan oleh komunikan dan ditangkap oleh komunikator berupa perilaku nonverbal yang dilakukan secara tidak disengaja atau alami dilakukan.

Pola komunikasi pada penerapan praktik meditasi pada sekolah berbasis Buddhis di Banten memiliki tipe pola komunikasi pelengkapan (complementary relationship) dengan jenis pola komunikasi interaksional. Pola komunikasi dengan tipe dan jenis seperti ini berarti pada praktik pertukaran pesan antara komunikator dengan komunikan berjalan saling melengkapi dimana tidak ada upaya untuk mendominasi dari komunikan saat komunikator menyampaikan pesan dan pola ini berjalan secara dua arah dan feedback tidak secara langsung muncul namun terus menerus dilakukan sampai terjadi internalisasi dan terbentuk karakter siswa yang sesuai harapan pemerintah, sekolah dan orangtua.

Penyelenggara pendidikan khususnya pendidikan Buddhis dapat mengadopsi model pola komunikasi yang sesuai dengan kondisi dan kebijakan sekolah sebagaimana tergambar dari 8 sekolah berbasis Buddhis di Banten. Pengambil kebijakan baik lokal maupun nasional dapat menggunakan pola komunikasi salah satu atau beberapa sekolah untuk menjadi percontohan dalam penerapan praktik meditasi di tempat lain. Peneliti, mahasiswa, praktisi pendidikan dan praktisi komunikasi dapat memanfaatkan penelitian ini untuk membuat suatu pola komunikasi yang lebih efektif dalam penerapan praktik meditasi di sekolah.

\section{DAFTAR REFERENSI}

Anggraini, F. (2018) 'Gangguan Proses Komunikasi Dalam Home Schooling Antara Ayah Dan Anak', E-Komunikasi, 6(1).

Arikunto, S. (2010) Prosedur Penelitian Suatu Pendekatan Praktik. Jakarta: Rineka Cipta.

BBC.com (2018) Kekerasan terhadap siswa masih marak, guru berdalih 'demi kedisiplinan. Available at: https://www.bbc.com/indonesia/indonesia -44925805 (Accessed: 26 January 2021).

Bogdan, R. and Taylor, S. . (1975) Introduction to Qualitative Research Method. New York: John Willey and Sons.

Halford, G. S. (2016) 'Cognitive developmental theories', The Curated Reference Collection in Neuroscience and Biobehavioral Psychology, (December 2015), pp. 298308 . doi: 10.1016/B978-0-12-8093245.05787-4.

Heider, F. (1958) The Psychology of Interpersonal Relations. New York: John Wiley \& Sons, Inc.

Himi, B. (2010) The Path of Purification: Visuddhimagga / Buddhaghosa Himi; tr. By Nyanamoli Himi. Kandy: Buddhist Publication Society.

Holton, V. and Dent, F. E. (2007) 'Developing Effective Communication Skills', Journal of Oncology Practice. London: Palgrave Macmillan UK, 3(6), pp. 314-317. doi: 10.1200/JOP.0766501.

Kristofer, I. and Susanto, E. H. (2019) 'Pola Komunikasi Dalam Upacara Adat Teapai di Lingkup Etnis Tionghoa Jakarta', Koneksi, 2(2), p. 387. doi: 10.24912/kn.v2i2.3914.

Kurniawan, D. (2018) 'Komunikasi Model Laswell Dan Stimulus-Organism-Response Dalam Mewujudkan Pembelajaran Menyenangkan', Jurnal Komunikasi Pendidikan, 2(1), p. 60. doi: 10.32585/jkp.v2i1.65. 
Littlejohn, S. W. and Karen A Foss (2009) Teori Komunikasi, Theories of Human Communication, Edisi Sembilan. Jakarta: Salemba Humanika.

Mashabi, S. (2020) LPSK: Kekerasan Seksual di Sekolah Cukup Tinggi. Available at: https://nasional.kompas.com/read/2020/0 8/06/16420041/lpsk-kekerasan-seksual-disekolah-cukup-tinggi (Accessed: 26 January 2021).

Matuzzahara, P., Sardi, I., \& Nurfathiya, P. (2020) 'Analisis Gangguan (Noise) dalam Proses Komunikasi dengan Penerapan Teknologi Padi Sawah di Desa Penapalan Kecamatan Tengah Ilir Kabupaten Tebo', Jurnal Ilmiah Sosio-Ekonomika Bisnis, 22(2), pp. 58-68. doi: 10.22437/jiseb.v22i2.8703.

Mauliya, A. (2019) 'Perkembangan Kognitif pada Peserta Didik SMP (Sekolah Menengah Pertama) Menurut Jean Piaget', ScienceEdu, 川(2), p. $86 . \quad$ doi: 10.19184/se.v2i2.15059.

Miles, M. B. and A. Michael Huberman (1992) Analisis Data Kualitatif: Buku Sumber Tentang Metode-metode Baru. 1st edn. Jakarta: Penerbit Universitas Indonesia.

Milgram, S. (1974) Obedience to Authority: An Experimental View. New York: Harper and Row.

Moleong, L. . (2011) Metodologi Penelitian Kualitatif Edisi Revisi. Bandung: PT. Remaja Rosdakarya.

Muhibah, S. (2020) 'Model Pengembangan Pendidikan Karakter Melalui Pendidikan Agama Di Perguruan Tinggi: Studi Kasus Di Universitas Tirtayasa Banten', EDUKASI: Jurnal Penelitian Pendidikan Agama dan Keagamaan, 18(1), pp. 54-69. doi: 10.32729/edukasi.v18i1.683.

Muin, A. (2013) 'Penguatan Karakter Melalui Pendidikan Islam Di Tk Mawaddah Kota Banjarmasin', EDUKASI: Jurnal Penelitian Pendidikan Agama dan Keagamaan, 11(2), pp. 199-217. doi: 10.32729/edukasi.v11i2.434.

Nasa, R. and Nuwa, G. (2019) 'Penguatan Nilai Karakter melalui Kegiatan Meditasi Kitab Suci di Sekolah Menengah Pertama Seminari Maria Bunda Segala Bangsa Maumere Nusa Tenggara Timur', Jurnal Pancasila Dan Kewarganegaraan, 4(2), pp. 53-61. doi: 10.24269/jpk.v4.n2.2019.

Pinazo, D., García-Prieto, L. T. and GarcíaCastellar, R. (2020) 'Implementation of a program based on mindfulness for the reduction of aggressiveness in the classroom', Revista de Psicodidáctica (English ed.). Universidad de Pa\&iacute;s Vasco, 25(1), pp. 30-35. doi: 10.1016/j.psicoe.2019.08.003.

Prasetyo, M. A. M. and Anwar, K. (2021) 'Karakteristik Komunikasi Interpersonal serta Relevansinya dengan Kepemimpinan Transformasional', Jurnal Komunikasi Pendidikan, 5(1), p. 25. doi: 10.32585/jkp.v5i1.1042.

Rose, C. and Malcolm J. Nicholl (2002) Accelerated Learning For The 21th Century: Cara Belajar Cepat Abad XXI. Jakarta: Nuansa.

Setyadi, D., Kustiani and Sukodoyo (2020) 'Makna Meditasi Vipassana bagi Mahasiswa Sekolah Tinggi Agama Buddha Syailendra', Jurnal Pencerahan, 13(1), pp. 52-61. doi: 10.5874/jfsr.14.2_70.

Sivaramappa, B. et al. (2019) 'Effect of anapanasati meditation on verbal aggression: A randomized controlled trial', Complementary Therapies in Clinical Practice, 36(July 2018), pp. 77-81. doi: 10.1016/j.ctcp.2019.06.004.

Sugianto (2018) 'Pembiasaan Meditasi pada Siswa Sekolah Dasar Berciri Buddhis di Jakarta dan Tangerang', Vijjacariya, 5(1), p. 95.

Sugiyono (2011) Metode Penelitian Kuantitatif, Kualitatif, dan R\&D. Bandung: CV Alfabeta.

West, R. and Lynn H. Turner (2012) Pengantar Teori Komunikasi Analisis dan Aplikasi. Jakarta: Salemba Humanika.

Yuli, P., Subawa, P. and Suparya, I. K. (2020) 'Peningkatan Hasil Belajar Siswa Sekolah Dasar Melalui Penerapan Model Pembelajaran Examples Non Examples Berbantuan Media Audio Visual', 1(2), pp. 103-112. 